Mexico

Youth

\title{
Strengthen Education on Adolescent Reproductive Health
}

OR Summary 36

\section{FINAL REPORT PENDING}

Young people in Mexico have a general knowledge of reproductive health, but their weak understanding of reproductive physiology and sexually transmitted infections makes them vulnerable to the consequences of risky behavior. Program managers should strengthen education on adolescent reproductive health for both young people and service providers.

\section{Background}

Unprotected sex among Mexico's young people often leads to unplanned pregnancy and unwanted births — consequences affecting the lives and opportunities of girls and boys alike. Unprotected sex also puts young people at risk of sexually transmitted infections (STIs) including HIV.

From 1999 to 2002 FRONTIERS worked with the nongovernmental organization MEXFAM to test the feasibility, effectiveness and cost of community-, clinic-, and school-based interventions to improve the reproductive health of youth aged 10 to 19 . The interventions were introduced through MEXFAM's Young People Program (YPP). Eight cities were selected as intervention sites, and four similar cities served as control sites. In the intervention sites, researchers worked with YPP coordinators and "multipliers" local community members such as teachers, community leaders, health care providers, and peer educators - who attended and subsequently taught courses on adolescent reproductive health. In the community intervention, multipliers conducted outreach through individual and group events such as plays, sports events, parades, and concerts. In the clinic-based component, providers offered youth-friendly services at their health facilities. Four of the intervention cities also received a school-based intervention in which trained teachers conducted events to strengthen existing sex education programs.

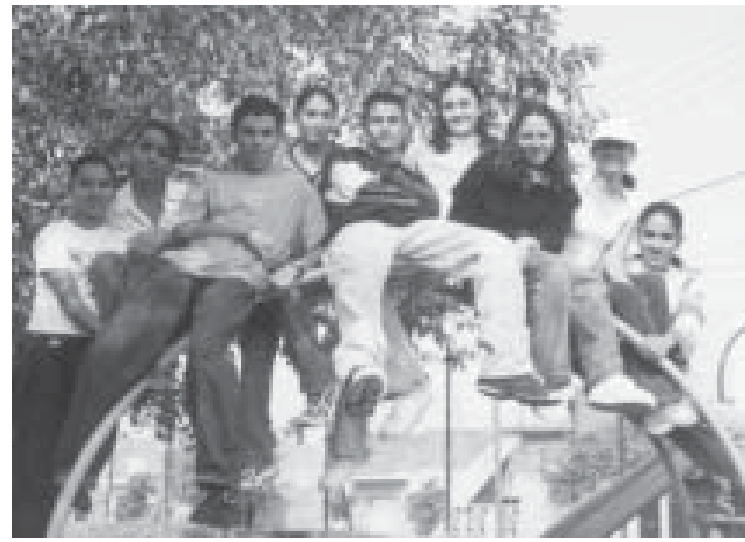

\section{Findings}

- Over 14,000 students, parents, and teachers attended courses and talks given by YPP coordinators and multipliers. Most adolescents (about 70 percent) reported that they had received sex education at school. The 100 participating providers reported that they had given over 60,000 medical services to adolescents, more than half related to reproductive health.

- Awareness of contraception was high and increased over time, with the proportion of youth knowing about family planning rising from 57 percent to 66 percent. Youth in all groups knew about six methods at baseline and endline. Knowledge of how to use a method was mixedfor example, only 20 percent of adolescents knew that pills must be taken every day. Among adolescents who knew about contraception, the condom was almost universally known. Over 80 
percent of adolescents had some knowledge of correct condom use.

- Knowledge of HIV/AIDS increased from 63 percent to 85 percent; similar increases took place at both intervention and control sites. Among those who had heard of HIV/AIDS, 83 percent mentioned sexual relations and over 30 percent mentioned blood transfusions as means of transmission. Knowledge of condoms as a means of protection increased from 56 percent to 78 percent. Less than 5 percent of youth surveyed mentioned fidelity to one partner as a means of avoiding HIV. In addition, less than half of adolescents surveyed following the intervention had heard of other sexually transmitted infections.

- Sexual activity is generally low. Of youth aged 10 to 19 , only 10 percent had sexual experience at baseline (and 11\% at endline) and 43 percent of experienced adolescents were either married or cohabiting. Nearly all sexual activity began after age 14 . Both before and after the intervention, and in both experimental and control groups, boys were at least twice as likely as girls to use a method (see Table). The great majority obtained the method - most often a condom — from a pharmacy $(85 \%)$ rather than a government clinic $(6 \%)$.

\begin{tabular}{|l|c|c|c|c|}
\hline \multicolumn{5}{|c|}{ Sexual Experience of Youth 10-19 at Intervention and } \\
Control Sites, 2002 \\
\hline & $\begin{array}{l}\text { Combined } \\
\text { Intervention (\%) }\end{array}$ & \multicolumn{2}{l|}{ Control (\%) } \\
\hline & $\begin{array}{l}\text { Boys } \\
(\mathrm{n}=591)\end{array}$ & $\begin{array}{l}\text { Girls } \\
(\mathrm{n}=663)\end{array}$ & $\begin{array}{l}\text { Boys } \\
(\mathrm{n}=309)\end{array}$ & $\begin{array}{l}\text { Girls } \\
(\mathrm{n}=352)\end{array}$ \\
\hline $\begin{array}{l}\text { Sexually } \\
\text { experienced }\end{array}$ & 11 & 7 & 13 & 11 \\
\hline $\begin{array}{l}\text { Age at first } \\
\text { sex }\end{array}$ & 15.7 & 15.8 & 15.6 & 16.1 \\
\hline $\begin{array}{l}\text { Used } \\
\text { method at } \\
\text { first sex }\end{array}$ & 62 & 21 & 50 & 22 \\
\hline
\end{tabular}

- A comparison between intervention and control areas showed few behavioral changes that could be attributed to the intervention. This may have been due to the very large catchment areas, contamination in the implementation of the intervention, or additional social factors that affected attitudes and behaviors.

- While positive changes occurred in control groups as well as experimental areas, analysis showed knowledge of contraceptives and use of reproductive health services were significantly stronger among youth who had been directly exposed to the YPP interventions.

- Marginal costs in both intervention sites were similar, about US $\$ 235,000$. The school-based intervention was costly, due to the high nonfinancial costs of about $\$ 100,000$ (such as staff time and reallocation of staff tasks). The community activities had the highest financial costs (about $\$ 40,000$ to $\$ 60,000$ ), reflecting the varied scale and frequency of activities.

\section{Utilization}

- MEXFAM has adopted several project management strategies introduced during the project. These include: a new information system focusing on data collection for on-site decisionmaking; new criteria and followup procedures for volunteers; and a focus on innovation in programming for youth.

\section{Policy Implications}

- Interventions to improve young people's access to reproductive health services should develop comprehensive training for providers that includes service goals and indicators to measure service improvements. Programs should also target pharmacists as major health care providers for youth.

September 2003

Durá, Maricela. 2003. "Improving the Reproductive Health of Youth in Mexico.” FRONTIERS Final Report. Washington, D.C.: Population Council, in press. For more information contact: Population Council, Apartado Postal 21-152, C.P. 04021, México Tel: 52-55-5999-8630; Fax: 52-55-5554-1226; E-mail: disemina@ popcouncil.org.mx

This project was conducted with support from the U.S. AGENCY FOR INTERNATIONAL DEVELOPMENT under Cooperative Agreement Number HRN-A-00-98-00012-00.

(1) Population Council 